\title{
THE USE OF HALOTHANE IN A PATIENT WITH ASYMMETRICAL SEPTAL HYPERTROPHY: A CASE REPORT
}

\author{
John A. ReITAn and Richakd G. Wright
}

\begin{abstract}
An elderly patient with demonstrated asymmetrical intraventricular septal hypertrophy and ventriculo-aortic pressure gradient was anaesthetized with nitrous oxide with oxygen, narcotic, and muscle relaxant for abdominal surgery. In addition to the cardiovascular variables customarily monitored, a systolic time interval (STI) measured from the $Q$ wave of the ECG to the foot of the radial pulse (the QF interval) was calculated in milliseconds beat-to-beat by a computer. With anaesthesia, and particularly following the beginning of operation, the QF interval lengthened as an indication of either decreased cardiac inotropy or increased pressure gradient across the aortic outflow tract. When halothane 0.25 per cent was added to the anaesthetic mixture, the QF interval shortened by about 20 milliseconds without an observed change in direct arterial pressure. Since halothane is a cardiac depressant and normally lengthens the STI, it apparently relaxed the muscular stenosis of the ventricular outflow tract and reduced the pressure gradient and, subsequently, the QF interval. By measuring cardiovascular function with this STI, the beneficial action of cardiac depression from low-dose halothane was observed, which would have escaped detection by common monitoring indices.
\end{abstract}

KEY WORDS: HEART, asymmetrical intraventricular septal hypertrophy; ANAESTHESIA, hatothane; MONITORING, systolic time interval.

THE USE OF halothane has been advocated for anaesthesia in patients with obstructive asymmetrical intraventricular septal hypertrophy, to reduce the ventriculo-aortic pressure gradient. Reports on monitoring the haemodynamic effects of the defect generally have used either invasive cardiac catheterization or echocardiographic technics for verification of the obstruction. ${ }^{2.3}$ We recently anaesthetized a patient with idiopathic hypertrophic subaortic stenosis (IHSS) for nonvascular surgery and followed the circulatory changes by monitoring systolic time interval (STI) in addition to the customary monitoring equipment.

\section{CAse RePORT}

A 64-year-old man with an endoscopic biopsy diagnosis of gastric carcinoma was scheduled for operation for therapeutic staging purposes. He

John A. Reitan, M.D. Associate Ptofessor; Richard G. Wright, M.D., Assistant Professor; Department of Anesthesiology, University of California, School of Medicine, Davis, California 95616, U.S.A

Correspondence to: John A. Reitan, M.D., Department of Anesthesiology, University of California, School of Medicine, Davis, California 95616. 154 suffered from gout, chronic ethanol abuse, degenerative joint disease, and hypertension. Four years before this hospitalization a diagnosis of IHSS was made following an echocardiographic examination and cardiac catheterization for a marked systolic murmur, increased by exercise. At that time a ventriculo-aortic gradient of $7.3 \mathrm{kPa}$ ( 55 torr) was found. A recent 20 pound weight loss had weakened the patient and caused him to decrease his therapeutic propranolol dosage for IHSS to $40 \mathrm{mg}$ four times a day. His blood pressure was $16 / 10 \mathrm{kPa}$ (120/75 torr) and he showed signs of orthostatic hypotension. His liver function tests were abnormal and albumin was 2.8 gm per cent.

Before the exploratory laparotomy, radial artery and central venous cannulae were placed under local analgesia and $800 \mathrm{ml}$ of crystalloid solution was given intravenously to increase his circulating volume. Anaesthesia was induced slowly with thiopentone, fentanyl and a nitrous oxide-oxygen gas mixture. Metacurine was used for intubation and sustained muscle relaxation. Incremental intravenous doses of fentanyl and thiopentone were administered for maintenance of anaesthesia. Blood pressure rose slightly from $13.3 / 9.2$ to $14.6 / 10 \mathrm{kPa}$ ( $100 / 70$ to $110 / 75$ torr)

Can. Anaesth. Soc. J., vol. 29, no. 2, March 1982 
with surgery and pulse rate remained at 55-60 beats/minute in a sinus rhythm.

In order to gain knowledge of myocardial performance during this anaesthetic, we measured an STI called the QF interval. In this patient the QF interval increased from $225 \pm$ $3 \mathrm{msec}$ (mean $\pm 1 \mathrm{SD}$ ) before anaesthesia to $234 \pm 2 \mathrm{msec}$ at induction of anaesthesia to $245 \pm 2 \mathrm{msec}$ during the initial surgery. However, blood pressure was stable at 13.3-14.6/ 9.2-10 kPa (100-110/70-75 torr).

Soon after the start of operation halothane 0.25 per cent was added to the gas mixture and within two minutes the QF interval shortened to $226 \pm 2$ msec. Blood pressure and heart rate were unchanged. When halothane was turned off, the STI promptly increased by about 20 msec. Similar changes were observed when this sequence was repeated. By Student's " $t$ " test these reproducible changes in the QF interval with and without halothane were significant at $p<0.001$. The remainder of the anaesthetic included halothane 0.25 per cent and was uneventful. The QF interval remained in the 225 $230 \mathrm{msec}$ range. Inoperable liver and mesenteric metastases were found at surgery. The patient recovered from anaesthesia and surgery and underwent transient medical treatment.

\section{Discussion}

The QF interval measures the time in msec from the $Q$ wave of the ECG to the foot or upstroke of the peripheral pulse. It includes both the pre-ejection period (PEP) - the time from start of electrical activity in the ventricle to the onset of ejection of blood from the ventricle and the time for transmission $\left(T_{x}\right)$ of the pressure pulse to a peripheral site. Figure 1 illustrates the relationship between the $\mathrm{PEP}$ and $\mathrm{QF}$ intervals. Both of these STI's encompass the time it takes the left ventricle to build up pressure sufficient to eject blood into the aorta and the QF interval has been shown to correlate closely with the PEP at rest and with inotropic changes during anaesthesia. ${ }^{4}$ The QF was measured from the lead II ECG and radial artery pulse wave by a special purpose computer in real time. While the pulse wave was transduced directly from the artery in this report, it can be obtained transcutaneously for totally noninvasive monitoring.

Patients with intraventricular septal hypertrophy may have an effective outflow obstruction from the left ventricle which increases when cardiac inotropy is elevated. ${ }^{5}$ The relationship

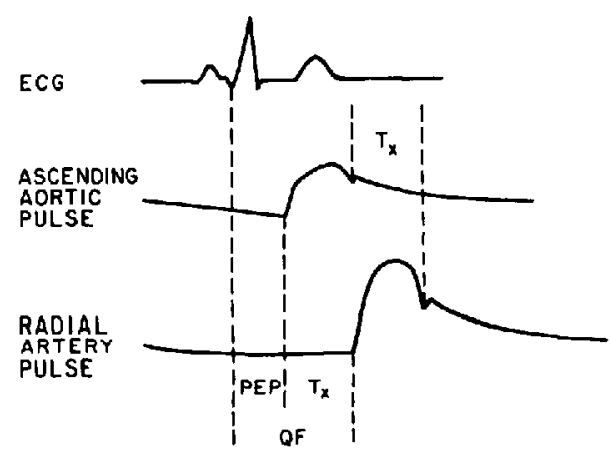

FIGURE I The ECG, ascending aortic pulse (AAP) and peripheral pulse (PP) are shown in their temporal relationship. The time from the $Q$ wave of the ECG to the beginning of blood ejection from the ventricle (the upstroke of AAP) is the cardiac preejection period (PEP). The time for pulse wave transmission to the periphery $\left(T_{x}\right)$, is noted as the delay between the upstrokes of AAP and PP or the difference between the incisuras of the two pulses. The QF interval includes PEP and $T_{x}$ and is measured from the Q wave of the ECG to the foot or upstroke of PP.

between left ventricular pressure and ascending aortic pressure in IHSS is illustrated schematically in Figure 2. The systolic ventriculo-aortic pressure gradient in this drawing is about 5.32 $\mathrm{kPa}\left(40\right.$ torr) and the pre-ejection period $\left(\mathrm{PEP}_{\mathrm{O}}\right)$

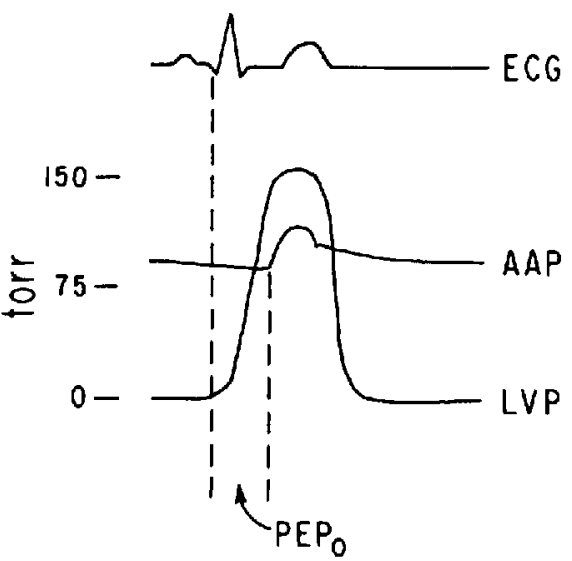

FIGURE 2 An artist's drawing of the ECG, ascending aortic pressure (AAP) and left ventricular pressure (LVP) in an idealized presentation of a case of IHSS. The subvalvular stenosis creates a gradient of approximately $5.32 \mathrm{kPa}$ (40 torr) - that is, ventricular ejection is delayed until LVP reaches $5.32 \mathrm{kPa}$ ( 40 torr) greater than aoric diastolic pressure. Consequently with this obstruction, $\mathrm{PEP}_{\mathrm{O}}$ is prolonged by the time it takes the ventricle to generate the excess pressure. 


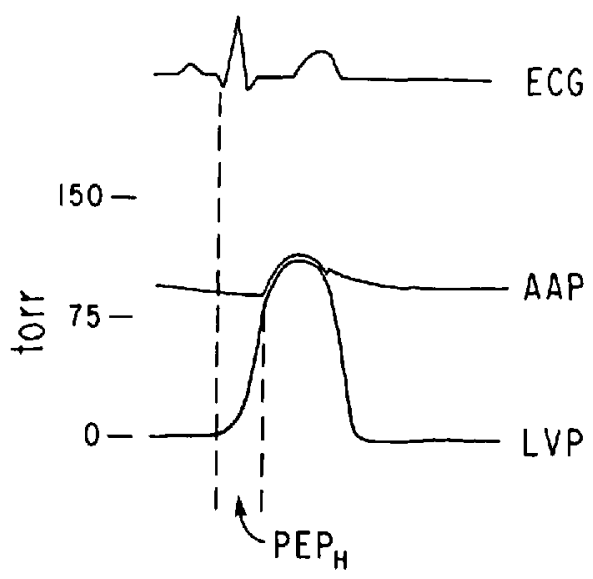

FigURE 3 When the heart is depressed chemically and sufficiently to relax the hypertrophied septum, the gradient between ventricular and aortic pressures disappears. In our patient low dose halothane was the agent used and shortened the pre-ejection period $\left(\mathrm{PEP}_{\mathrm{H}}\right)$ as the pressure necessary for ventricular ejection decreased.

is prolonged since more time than normal is necessary to develop pressure sufficient for ejection of blood beyond the obstruction. In our patient the $Q F$ interval increased from the pre-anaesthetic control by approximately 20 msec with the onset of surgery. This change would be due to lengthening of either the $T_{x}$ or PEP. $T_{x}$ is inversely proportional to the diastolic pressure $^{6}$ and since arterial pressure was relatively unchanged, the added $20 \mathrm{msec}$ in QF must have come from an increase in PEP.

The normal effect of halothane anaesthesia on PEP (and consequently QF) is a lengthening of the interval by decreasing cardiac inotropy. ${ }^{7}$ Conversely, in IHSS, exercise or sympathetic. stimulation similar to the neural excitation of surgery will increase the pressure gradient not unlike the situation with our patient. ${ }^{8}$ By adding low-dose halothane to the anaesthetic as a mild myocardial depressant, the gradient may be reduced sufficiently for ventricular pressure to fall and match aortic pressure (Figure 3). PEP shortens noticeably $\left(\mathrm{PEP}_{\mathrm{H}}\right)$ and, in our patient, was expressed as an equal decrease in the $\mathrm{QF}$ interval. Again, in this case, the diastolic arterial pressure remained stable so $T_{x}$ did not vary.

By following the STI in this patient with IHSS we were able to document the beneficial effects of appropriate myocardial depression from a volatile anaesthetic which would have escaped detection by common monitoring methods. While there was no overt change observed in peripheral blood pressure or heart rate, the $\mathrm{QF}$ interval measured a distinct increase in ventricular stress during surgery and its subsequent resolution by halothane.

\section{REFERENCES}

1. Kaplan, J.A. Cardiac Anesthesia. New York, Grune and Stratton, p. 197 (1979).

2. REDWOOD, D.R., SCHERER, J.L. \& EPSTEIN, S.E. Biventricular cineangiography in the evaluation of patients with asymmetric septal hypertrophy. Circulation 49: 1116 (1974).

3. Henry, W.L., Clarke, C.E., Glancy, D.L. \& EPSTEIN, S.E. Echocardiographic measurement of the left ventricular outflow gradient in idiopathic hypertrophic subaortic stenosis. N. Eng. J. Med. 288: 989 (1973).

4. List, W.F. Gravenstein, J.S. \& Spodick, D.H. Systolic Time Intervals, Berlin, SpringerVerlag, p. 273 (1980).

5. EPSTEIN, S.E., Moderator. NIH conference on asymmetric septal hypertrophy. Ann. Int. Med. 81: 650 (1974)

6. LiverANI, M. Cardiovascular monitoring in anesthesia: A new systolic time interval. Thesis for Ph.D. Degree, Stanford University, Stanford, California (1973).

7. Pierce, G.E. Morrow, A.G. \& Braunwald E. Idiopathic hypertrophic subaortic stenosis: III Intraoperative studies of the mechanism of obstruction and its hemodynamic consequences. Circulation Supplement IV, 30: 152 (1964).

8. Hasbrouck, J.D. \& Coleman, C.C. Effect of halothane on systolic time intervals. Anesth. Analg. 56: 524 (1977).

\section{RÉSUME}

Un patient âgé porteur d'une hypertrophie asymétrique du septurn interventriculaire avec un gradient aortique a subis une intervention abdominale sous anesthésie au protoxyde d'azole-axygène associé à un narcotique et un myorésolutif. En plus des paramètres cardiovasculaires habituels, on a monitoré l'intervalle systolique mesuré à partir de l'onde $Q$ de l'ECG jusqu'au début de la montée radiale (intervalle QF) calculé en millisecondes à chaque battement par un ordinateur. Durant l'anesthésie et surtout après le début de la chinurgie l'intervalle QF s'est allongé et ceci a été considéré soit comme une diminution de l'inotropie cardiaque ou une augmentation du gradient de pression à travers la chambre de 
chasse. Lorsque l'halothane 0.25 pour cent a été ajouté au mélange anesthésique, l'intervalle $Q F$ a diminué d'environ 20 millisecondes sans qu'on observe de changement de la tension artérielle. Comme l'halothane déprime la fonction cardiaque et augmente normalement l'intervalle systolique, on en conclut que cet agent a relaché la sténose musculaire située sur la chambre de chasse, réduit le gradient de pression et par la suite l'intervalle systolique. Par la mesure de l'intervalle systolique décrit plus haut on a pu montrer l'effet bénéfique de la dépression cardiaque causée pour une faible concentration d'halothane qui autrement aurait pu passer inaperçue avec les techniques habituelles de monitorage. 